\title{
ОБЩАЯ ХАРАКТЕРИСТИКА НАСЛЕДСТВЕННОГО ПРАВА
}

\author{
МАМЕДОВ Заур - доктор юридических наук, главный научный сотрудник \\ Института «История науки» Национальной Академии Наук Азербайджана \\ DOI:10.32782/EP.2020.1.20 \\ УДК 347.65/68
}

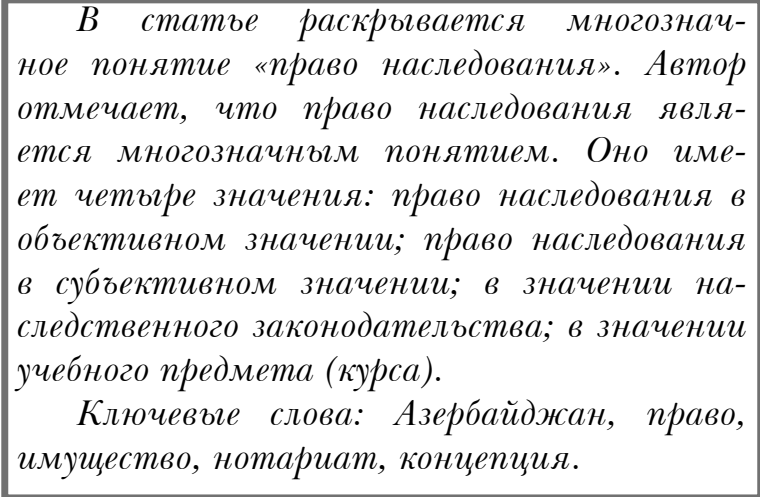

Право наследования является многозначным понятием. Оно имеет четыре значения: право наследования в объективном значении; право наследования в субъективном значении; в значении наследственного законодательства; в значении учебного предмета (курса).

В объективном значении под правом наследования понимается совокупность имущественных прав и обязанностей, которые могут быть переданными после смерти физического лица другим лицам, общественных отношений, возникающих при переходе некоторых неимущественных прав к другим лицам, а также правовых норм, регулирующих другие отношения, связанные наследованием.

Под правом наследования в субъективном значении, понимается мера поведения конкретного лица как наследника. Речь идет о праве конкретного лица являться наследником, быть призванным к наследова- нию, одним словом, о праве получить имущество умершего лица.

Право наследования в субъективном смысле - это субъективное право наследования. А субъективное право наследования считается одним из видов субъективного гражданского права.

Право наследования в третьем значении используется в значении наследственного законодательства. Под наследственным законодательством или законодательством о наследовании, понимается совокупность нормативно-правовых актов, регулирующих наследственные отношения, а также другие отношения, связанные с наследованием.

Наследственное право, как учебная дисциплина (курс), обучает право наследования являющейся подотраслью гражданского права, концепциям, теориям, доктринальным (научным) мыслям, учениям об этом праве.

Будучи как экономической, так и правовой категорией, связанной с процессом формирования и укрепления собственности, институт наследования, являющийся одним из правовых институтов, имеющих древнюю историю, с одной стороны, создает для собственника возможность реализации полномочий по распоряжению своим имуществом, а с другой, - выступает как одно из оснований возникновения права собственности [5, с. 5].

В.Н.Яковлев отмечает, что Римское наследственное право проистекает из глубо- 


\section{Цивільне, підприсмницьке, господарське та трудове право}

кой древности, названной первобытно-общинным строем. Долгий и сложный путь развития института наследования проходил через все известные социально-экономические формации: рабовладельческую, феодальную, капиталистическую, социалистическую. И каждая из этих формаций вносила свои коррективы в содержание наследственного права. Однако его суть оставалась прежней, древнеримской: имущественное правопреемство, составляющее содержание института наследования [9, с. 675].

Наследование является производным институтом, основанным на правопреемстве, то есть на переходе прав и обязанностей, принадлежащих одному лицу к другому лицу (другим лицам).

Как известно, правопреемство может быть общим и специальным. При специальном правопреемстве от одного лица к другим лицам переходят права и обязанности (либо только права или только обязанности) в одном или нескольких правоотношениях. При общем (универсальном) правопреемстве к другому лицу (другим лицам) права и обязанности переходят в неизменном виде как единое целое, причем в один и тот же момент. Наследование относится к общему правопреемству: наследство (наследственное имущество) переходит к наследникам в порядке универсального правопреемства, т.е. в неизменном виде, как единое целое, и в один и тот же момент [7, с. 98].

Тесно связанное с имущественными отношениями, право наследования в мусульманском праве подразделяется на две ветви: наследование по завещанию и фараиз, то есть наследство по закону. Мусульманин вправе завещать лишь одну треть своего имущества, завещание, превышающее данный предел, считается недействительным. В случае, если в составленном лицом завещании указано более трети имущества, наследник по завещанию должен отказаться от его принятия в пользу наследника по закону. Завещание составляется в присутствии двух свидетелей.

Согласно мусульманскому праву, то или иное лицо может завещать свое имущество любому другому лицу, независимо от рели- гиозной принадлежности. В случае, если завещатель в различное время составил несколько противоречащих друг другу завещаний, то обладающим юридической силой считается лишь последнее завещание.

Вместе с наследуемым имуществом по наследству переходят также имущественные права и обязательства завещателя. Удостоверенное завещание, как доказательство, играет определенную роль в судебном процессе.

При наследовании по закону, количество долей наследников нашло свое отражение в 11-й и 12-й аятах суры ан-Ниса (Женщины) в Коране: Aллах заповедует вам относительно ваших детей: мужчине достается доля, равная доле двух женщин. Если все дети являются женщинами числом более двух, то им принадлежит две трети того, что он оставил. Если же есть всего одна дочь, то ей принадлежит половина. Каждому из родителей принадлежит одна шестая того, что он оставил, если у него есть ребенок. Если же у него нет ребенка, то его наследуют родители, и матери достается одна треть. Если же у него есть братья, то матери достается одна шестая. Таков расчет после вычета по завещанию, которое он завещал, или выплаты долга. Ваши родители и ваши дети - вы не знаете, кто из них ближе и приносит вам больше пользы. Таково предписание Аллаха. Воистину, Аллах - Знающий, Мудрый (11-й аят).

Вам принадлежит половина того, что оставили ваши жены, если у них нет ребенка. Но если у них есть ребенок, то вам принадлежит четверть того, что они оставили. Таков расчет после вычета по завещанию, которое они завещали, или выплаты долга. Им принадлежит четверть того, что вы оставили, если у вас нет ребенка. Но если у вас есть ребенок, то им принадлежит одна восьмая того, что вы оставили. Таков расчет после вычета по завещанию, которое вы завещали, или выплаты долга. Если мужчина или женщина, которые оставили наследство, не имеют родителей или детей, но имеют брата или сестру, то каждому из них достается одна шестая. Но если их больше, то они имеют равные права на одну треть. Таков расчет после вычета по завещанию, 
которое он завещал, или выплаты долга, если это не причиняет вреда. Такова заповедь Аллаха, ведь Аллах - Знающий, Выдержанный (12-й аят).

В странах, где действуют нормы мусульманского права, при решении вопросов наследования, за основу берутся 180-й аят суры аль-Багара, а также 11-й и 12-й аяты суры ан-Ниса. В 180-й аяте суры аль-Багара говорится: «Когда смерть приближается к кому-либо из вас, и он оставляет после себя добро, то ему предписано оставить завещание родителям и ближайшим родственникам на разумных условиях. Такова обязанность богобоязненных».

В советский период $\mathrm{XX}$ столетия право наследования прошло сложный путь развития. В 1920 году Революционный Комитет Азербайджана издал Декрет об отмене наследования (ни в архивном фонде, ни в сборнике законов нет информации о том, в какой день и месяц 1920 года было отменено наследование, без упоминания дня и месяца указывается лишь, что в 1920 году был издан Декрет об отмене наследования). В Декрете говорилось: «Наследование, как по закону, так и по завещанию отменяется, все движимое и недвижимое имущество принадлежавшие собственнику, после его смерти считаются государственной собственностью Азербайджанской Советской Социалистической Республики». Согласно Декрету об отмене наследования, по наследству могли перейти лишь домашние предметы, не превышающие десяти тысяч рублей, и необходимое для трудовой деятельности имущество наследодателя.

В статьях 487-506 (4-м разделе) состоящего из 5 разделов, первого Гражданского Кодекса Азербайджанской ССР, принятого на 3-й сессии Центрального Исполнительного Комитета Азербайджана 16 июня 1923 года и вступившего в силу 8 сентября того же года, нашли отражение положения, связанные с наследованием. На основании статьи 487 указанного Кодекса, допускалось наследование по закону и по завещанию.

В последующие годы номера статей Гражданского кодекса, регулирующих наследственные отношения, и содержание некоторых статей были изменены. После из- менений вопросы наследования нашли отражение в статьях 487-506 Кодекса. Постановлением Центрального Исполнительного Комитета Азербайджана от 6 марта 1926 года в раздел «Право наследования» Гражданского кодекса было внесено изменение и предел имущества, переходящего по наследству (10 тысяч рублей), отменен.

В годы Второй мировой войны в законодательство в сфере права наследования были внесены некоторые изменения. Указом Президиума Верховного Совета СССР «О наследниках по закону и по завещанию» от 14 марта 1945 года ранее известные категории наследников по закону были дополнены двумя новыми категориями - утратившими трудоспособность родителями, а также братьями и сестрами. В соответствии с Указом была введена очередность призвания к наследованию по закону. В первую очередь подлежали призванию дети (в том числе усыновленные), супруг и нетрудоспособные родители умершего, а также другие нетрудоспособные лица, состоявшие на иждивении умершего не менее одного года до его смерти. Во вторую очередь призывались трудоспособные родители, а при их отсутствии - в третью очередь - братья и сестры умершего.

В связи с изданием Указа Президиума Верховного Совета СССР «О наследниках по закону и по завещанию» от 14 марта 1945 года Указом от 14 ноября 1947 года статья 498 Гражданского кодекса Азербайджанской ССР была дополнена примечанием следующего содержания:

«入ица, находящиеся в живых на день открытия наследства, а также находившиеся в утробе матери при жизни наследодателя и родившиеся после его смерти, считаются наследниками».

В Гражданском кодексе Азербайджанской ССР от 11 сентября 1964 года вопросам наследования были посвящены статьи 527-572.

Каждое государство, само создает наследственные правовые нормы, то есть общего наследственного права, применяемого во всех странах, нет.

На основании части 5 статьи 29 Конституции Азербайджанской Республики от 12 


\section{Цивільне, підприємницьке, господарське та трудове право}

ноября 1995 года государство гарантирует право на наследование. Для сравнения хотели бы подчеркнуть что кроме Украины, Туркмении и Киргизии, в Конституциях всех Стран Содружества Независимых Государств имеется Конституционная гарантия на право наследования. Однако, в Конституциях Украины, Туркмении и Киргизии не имеется норма, указывавшая на государственную гарантию о наследовании.

На основании статьи 1133 Гражданского кодекса Азербайджанской Республики, которая называется «Понятие наследования», имущество умершего лица (наследодателя) переходит к другим лицам (наследникам) в силу закона либо завещания либо по обоим основаниям [3].

Наследование по закону (переход имущества умершего к лицам, указанным в законе) наступает в том случае, если наследодатель не оставит завещания, либо завещание полностью или частично признано недействительным.

В настоящее время во всех странах Coдружества Независимых Государств нормы, связанные с наследством, нашли свое отражение в Гражданских кодексах этих стран. Статьи 1133-1325 нового Гражданского кодекса Азербайджанской Республики,ст. 1110-1185 ГК Российской Федерации, ст. 1216-1308 ГК Украины, ст. 1138-1190 ГК Республики Таджикистан, ст. 1118-1166 ГК Киргизской Республики, ст. 1112-1157 ГК Республики Узбекистан, ст. 1432-1575 ГК Республики Молдова, ст. 1038-1083 ГК Республики Казахстан, ст. 1128-1318 ГК Туркменистана и ст. 1031-1092 Республики Беларусь посвящены вопросам наследования.

Из республик, которые были в составе бывшего Советского Союза, только Әстонская Республика отказалась от кодификации гражданского права, выбрав путь разработки общего закона о регулировании гражданских отношений, и 28 июня 1994 года был принят Закон Эстонской Республики «Об общей части Гражданского кодекса». После этого началось принятие специальных законов, посвященных отдельным подотраслям и институтам гражданского права, в том числе Закона «О наследственном праве» Эстонской Республики от 15 мая 1996 года.
Указанный Закон, вступивший в действие с 1 января 1997 года, включает в себя восемь разделов и 174 статьи, которые достаточно подробно определяют эстонский наследственный правопорядок, в том числе в области регулирования наследования по закону, завещанию, договору, обязательной доли в наследстве и наследственного процесса. Но этот Закон действовал всего два года, так как в Әстонии с 1 января 2009 года вступил в силу новый Закон «О наследовании», который был принят 17 января 2008 года, состоящий из 190 статьи.

В Европе следующие нормативные акты регулируют наследственные отношения:

- в Австрии - Всеобщий Гражданский Кодекс Австрии от 1 июня 1811 года, вступивший в силу с 1 января 1812 года (с изменениями и дополнениями) (параграфы 532-824);

- в Болгарии - Закон о наследовании от 29 января 1949 года (действует с изм. 1950, 1985 и 1992 года гг.);

- в Венгрии - раздел Гражданского Кодекса Венгерской Республики 1959 г.(в ред. 1977 г.);

- в Германии - Германское гражданское уложение 1896 года (книга V «Наследственное право»);

в Испании - Гражданский Кодекс Испании 1889 г., титул III книги III; а также Закон о наследовании 11/1981 от 13 мая 1981 г.;

- в Италии - Гражданский Кодекс Италии 1942 года (книга вторая);

- в Польше - Гражданский Кодекс Республики Польша 1964 года;

- в Румынии - Гражданский Кодекс Румынии 1865 года;

- во Франции - Гражданский Кодекс 1804 года, два титула книги III Французского Гражданского Кодекса (далее ФГК) «О различных способах, которыми приобретается собственность»: титул I «О наследовании»и титул II «О прижизненном дарении и завещании». Наследование по закону рассматривается в ФГК отдельно от наследования по завещанию, которое регулируется в тесной связи с прижизненными дарениями. Әто объясняется наличием в законе общих норм, регулирующих поря- 
док безвозмездного приобретения имущества;

в Чехии - Гражданский Кодекс 1963 года (в ред. 1992 г.);

- в Швейцарии - книга III Швейцарского Гражданского Кодекса «О наследствах». Регламентирование ряда вопросов (в частности, связанных с составлением завещания) Кодекс относит к компетенции кантонов;

- в Сербии - Закон о наследовании Республики Сербия от 1974 года (с дополнениями от 1979 г.),

в Черногории - Закон о наследовании Республики Черногория от 1975 года (с доп. 1978 г.);

в Хорватии Закон о наследовании Республики Хорватия от 1965 года (с доп. 1978 года).

При регулировании наследственных отношений применяются также некоторые нормативные акты, действующие наряду с Гражданским кодексом. В Венгрии, например, это Закон 1974 года о браке, семье и опеке (с изм. и доп.), Закон 1991 года о нотариусах; Приказ Министра Юстиции 1984 года «О нотариусах и некоторых видах нотариального производства». В Польше таким сопутствующим нормативным актом является Закон о нотариате 1951 года (с послед. изм.) [8, с. 379-380] и др.

Как правильно указывает профессор Г.Г.Черемных, в странах континентального права наследственное право переняло многие институты римского наследственного права, адаптировав некоторые институты к собственным национальным особенностям.

Наследственное право зарубежных стран исходит из общих принципов возможности наследования по закону и по завещанию, причем по общему правилу наследование по закону рассматривается как «наследование без завещания», то есть приоритет имеет наследование по завещанию. Законодательство о наследовании исходит из незыблемости свободы воли наследодателя, который вправе самостоятельно распорядиться своим имуществом, оставив его любым лицам, как из числа родственников так и лиц, не имеющих с ним родственной связи $[8$, с. 378$]$.
Вместе с тем в порядке наследования, как по закону, так и по завещанию в странах континентальной Европы и в странах общего права имеются существенные различия. Во-первых, в странах общего права наследственное имущество переходит к наследникам не непосредственно, а через так называемого личного представителя. Он обычно назначается судом из числа заинтересованных лиц и называется администратором (Administrator). В случае если распорядитель наследства указывается самим наследодателем в завещании, он утверждается судом и именуется исполнителем (Executor).

Аичный представитель определяет объем наследственного имущества («наследственную массу»), управляет им в режиме доверительного собственника, удовлетворяет претензии кредиторов наследодателя, ведет другие его дела; распределяет наследство между наследниками, представляет по требованию суда отчет о произведенных действиях и возмещает ущерб, причиненный его недозволенными действиями наследникам или кредиторам наследодателя.

Во-вторых, в странах общего права имеет место привилегированное положение пережившего супруга как наследника [6,c. 214-215].

При исследовании законодательства стран Содружества Независимых Государств мы видим, что только Гражданский Кодекс Украины вступивший в силу с 1 января 2004 года, признает наследственный договор одним из основанием наследования. О.Е.Блинков отмечает: «Договорной элемент сыграл большую роль в романо-германском праве для развития свободы распоряжения имуществом на случай смерти в пострецепционный период, что вылилось в конструировании отрицаемого римскими юристами такого основания наследования, как договор. Наследственный договор изначально имел германское происхождение, а наличие его в некоторых европейских наследственно-правовых системах объясняется рецепцией германского права в конце XIX - начале XX в.» [2, с. 34].

В.О.Аболонин указывает, что в системе наследственного права немецкоязычных стран (Германия, Австрия, Швейцария) на- 


\section{Цивільне, підприємницьке, господарське та трудове право}

следственные договоры занимают особое место и существенно отличаются от других форм передачи имущества по наследству. Общим для законодательства трех стран является то, что наследственные договоры совмещают в себе признаки гражданско-правового договора и завещания, а также могут быть расторгнуты в одностороннем порядке только в случаях, прямо установленных в законе, и с соблюдением всех формальных требований.

Законодательством Германии, Австрии и Швейцарии допускаются одно-, двух- и многосторонние наследственные договоры, т.е. договоры, согласно которым одна сторона определяет в качестве наследника другую сторону, когда обе стороны договора определяют в качестве наследников друг друга или когда стороны договора определяют наследником третье лицо (или лица). В отличие от Германии законодательство Австрии и Швейцарии придерживается правила, согласно которому наследственный договор может заключаться только между супругами или лицами, намеревающимися вступить в брак. Гражданское Уложение Германии, напротив, не предусматривает наличие брачных отношений в качестве обязательного условия заключения наследственного договора, что позволяет использовать данную конструкцию в том числе однополыми союзами, которые не имеют возможности регистрации брака в соответствии с действующим законодательством.

Отличительной особенностью швейцарской конструкции наследственного договора является то, что она допускает заключение так называемого негативного договора, позволяющего лицу, обладающему обязательной долей в наследстве, отказаться от своего права за встречное предоставление со стороны наследодателя, которое может быть передано ему еще при жизни последнего.

Законодательство трех стран предусматривает обязательное нотариальное удостоверение наследственного договора, которое также имеет ряд дополнительных признаков (устное волеизъявление, присутствие свидетелей и т.д.) [1, с. 6-8].
Согласно параграфу 2274 Гражданского Уложения Германии, наследодатель только сам может заключить наследственный договор. То есть, Германское законодательство не разрешает заключать наследственный договор с представителем наследодателя.

На основании ст. 512 Гражданского кодекса Швейцарии наследственный договор заключается с участием двух свидетелей.

В соответствии со статьей 1302 Гражданского кодекса Украины, по наследственному договору одна сторона (приобретатель) обязуется выполнять распоряжения другой стороны (отчуждателя) и в случае его смерти приобретает право собственности на имущество отчуждателя [4].

Отчуждателем в наследственном договоре могут быть супруги, один из супругов или другое лицо. Приобретателем в наследственном договоре может быть физическое или юридическое лицо (ст. 1303 ГК Украины).

Ст. 1304 ГК Украины устанавливает требования к форме наследственного договора. Согласно данной статье, наследственный договор заключается в письменной форме и удостоверяется нотариально, а также подлежит государственной регистрации в Наследственном реестре в порядке, утвержденном Кабинетом Министров Украины.

Әто требование применяется независимо от того, является предметом наследственного договора недвижимое или движимое имущество.

Наследственный договор Украины по своей природе похож на договор ренты, но на основании договора ренты право собственности на имущество получателя ренты возникает сразу, а согласно наследственному договору право собственности приобретателя возникает после смерти отчуждателя.

На основании наследственного договора возникают определенные обязательства, его содержание состоит в том, что приобретатель в наследственном договоре может быть обязан совершить некоторые действия имущественного или неимущественного характера до открытия наследства или после его открытия. Әтот договор является возмездной сделкой. 
Наследственным договором с участием супругов может быть охвачено как имущество, принадлежащее обоим супругам на праве общей совместной собственности, так и имущество, принадлежащее каждому из них. Заключение договора по поводу имущества, которое является личной собственностью одного из супругов, осуществляется этим лицом самостоятельно. Согласия другого супруга на заключение такого договора не требуется.

С целью недопущения перехода имущества, являющегося предметом наследственного договора третьим лицам, нотариус одновременно с удостоверением настоящего договора накладывает на указанное имущество запрет на отчуждения. Завещание, которое отчуждатель составил относительно имущества, указанного в наследственном договоре, является ничтожным. Отчуждатель вправе назначить лицо, которое будет осуществлять контроль за выполнением наследственного договора после его смерти. В случае отсутствия такого лица контроль за выполнением наследственного договора осуществляет нотариус по месту открытия наследства (ст. 1307 ГК Украины).

Основное отличие наследственного договора от завещания состоит в том, что этот договор не может быть аннулирован в одностороннем порядке.

На наш взгляд, наследственный договор может реализовать интересы наследодателя и приобретателя, по этой причине целесообразно было бы добавить в Гражданский кодекс Азербайджанской Республики 75-ю главу под названием «Наследственный договор». Предлагаем, при подготовке 75-ой главы, в которой найдут свое отражение статьи 1326-1332 Гражданского кодекса Азербайджанской Республики, учесть опыт в данной сфере Германии, Австрии, Швейцарии и Украины и эти статьи изложить в нижеуказанной редакции:

- Статья 1326 Гражданского кодекса: «Понятие наследственного договора»;

- 1326.1. «По наследственному договору одна сторона (приобретатель) обязуется выполнять распоряжения другой стороны (отчуждателя) и в случае его смерти приоб- ретает право собственности на имущество отчуждателя»;

1326.2. «В наследственном договоре вместо сторон не могут выступать их представители».

- Статья 1327 Гражданского кодекса: «Стороны в наследственном договоре»;

- «Отчуждателями в наследственном договоре могут быть супруги, один из супругов или иное совершеннолетнее физическое лицо, а приобретателями могут быть совершеннолетние физические лица, также юридические лица»;

- Статья 1328 Гражданского кодекса: «Форма наследственного договора»;

- «Наследственный договор подлежит нотариальному удостоверению и государственной регистрации в соответствующем органе исполнительной власти (Министерстве Юстиции Азербайджанской Республики)»;

Статья 1329 Гражданского кодекса: «Обязанности приобретателя в наследственном договоре»;

- «Приобретатель должен совершить действия имущественного или неимущественного характера предусмотренные в наследственном договоре, до открытия наследства и после его открытия»;

- Статья 1330 Гражданского кодекса: «Особенности наследственного договора заключенные с участием супругов»;

1330.1. «Предметом наследственного договора может быть имущество, принадлежащее супругам на праве общей совместной собственности, а также имущество, являющееся собственностью любого из супругов»;

1330.2. «Наследственным договором может быть предусмотрено, что в случае смерти одного из супругов наследственное имущество переходит к другому супругу, а в случае смерти другого супруга к приобретателю»;

- Статья 1331 Гражданского кодекса: «Обеспечение наследственного договора»;

- 1331.1. «На имущество, определенное в наследственном договоре, нотариус или другое должностное лицо, совершающее нотариальные действия налагает запрет на отчуждение»; 


\section{Цивільне, підприсмницьке, господарське та трудове право}

1331.2. «Завещание, относительно имущества указанного в наследственном договоре, является ничтожным».

1331.3. «Отчуждатель вправе назначить лицо, которое будет осуществлять контроль за выполнением наследственного договора после его смерти». При отсутствии такого лица, нотариус по месту открытия наследства или другое должностное лицо, совершающее нотариальные действия, осуществляет контроль за выполнением наследственного договора»;

- Статья 1332 Гражданского кодекса: «Расторжение наследственного договора»;

- 1332.1. «Наследственный договор, может быть расторгнут судом по требованию отчуждателя в случае невыполнения приобретателем его распоряжений»;

- 1332.2. «Наследственный договор может быть расторгнут судом по требованию приобретателя в случае невозможности выполнения распоряжений отчуждателя».

\section{入итература}

1. Аболонин В.О. Общая характеристика наследственного договора в праве Германии, Австрии и Швейцарии // Нотариальный вестник, 2010, № 02, с. 3-9

2. Блинков О.Е. Общие тенденции развития наследственного права государств участников содружества независимых государств и Балтии: Автореф. дис. ... докт. юр. наук. Юридический институт Московской академии экономики и права, М., 2009, 57 с.

3. Гражданский кодекс Азербайджанской Республики от 28 декабря 1999 года. https://online.zakon.kz/Document/?doc id $=30420111$

4. Гражданский кодекс Украины от 16 января 2003 года. https://meget.kiev.ua/ kodeks/grazdanskiy-kodeks/

5. Гришаев С.П. Наследственное право: Учебное пособие. М.: Юрист, 2003, 125 с.

6. Зенин И.А. Гражданское и торговое право зарубежных стран: Учебное пособие. М.: Юрайт, 2011, 247 с.

7. Нотариат и нотариальная деятельность: учебное пособие для курсов повышения квалификации нотариусов / Под ред. В.В. Яркова, Н.Ю. Рассказовой. М.: Волтерс Клувер, 2009, 656 с.
8. Черемных Г.Г. Наследственное право России: Учебник. М.: Әксмо, 2009, 512 с.

9. Яковлев В.Н. Древнеримское частное право и современное российское гражданское право. М.: Волтерс Клувер, 2010, 960 c.

Zaur Mammadov, Doctor of Juridical Science,

CHIEF RESEARCH WORKER OF THE «HISTORY OF SCIENCE» INSTITUTE OF THE NATIONAL ACADEMY OF SCIENCES OF AZERBAIJAN

The article states that the right of inheritance is a multi-valued concept. It has four meanings: the right to inherit in an objective sense; inheritance law in a subjective sense; in the meaning of inheritance law; in the meaning of the subject course.

In objective meaning, the right of inheritance is understood as a set of property rights and obligations that can be transferred after the death of an individual to other persons, public relations arising from the transfer of certain non-property rights to other persons, as well as legal norms governing other relations related to inheritance.

Under the right of inheritance in the subjective sense, is understood the measure of behavior of a specific person as an heir. We are talking about the right of a particular person to be an heir, to be called to inherit, in a word, about the right to receive the property of a deceased person.

The right of inheritance in the subjective sense is the subjective right of inheritance. A subjective right of inheritance is considered one of the types of subjective civil law.

The right of inheritance in the third meaning is used in the meaning of inheritance law. Under the inheritance law or legislation on inheritance, we mean the totality of legal acts regulating inheritance relations, as well as other relations related to inheritance.

Inheritance law, as a discipline course, teaches the law of inheritance which is a subbranch of civil law, concepts, theories, doctrinal (scientific) thoughts, teachings about this law.

Key words: Azerbaijan, law, property, notary, concept. 